\title{
Aumento na produção de biomassa de levedura em propagador aerado por processo descontínuo e semicontínuo para produção de cachaça
}

\author{
Increase in yeast biomass production in batch and semi-continuous \\ aerated propagators in the production of sugarcane spirit
}

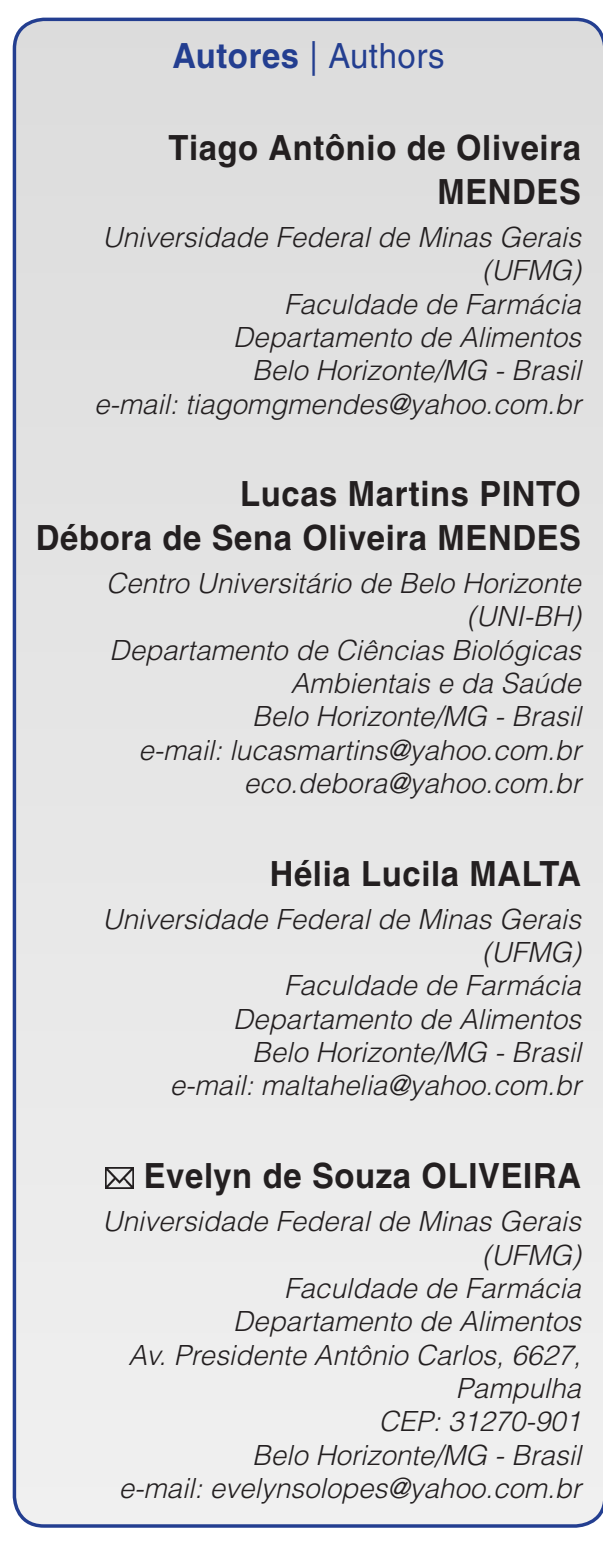

Autor Correspondente / Corresponding Author

Recebido / Received: 13/09/2011 Aprovado / Approved: 18/02/2013 Publicado / Published: jun./2013

\section{Resumo}

Tradicionalmente, a propagação de leveduras é feita diretamente dentro das dornas de fermentação nas fábricas de cachaça de alambique. Contudo, estas não dispõem de quaisquer dispositivos que permitam otimizar a propagação, na qual a eficiência da aeração é fator primordial para a predominância do metabolismo respiratório, que permite maximizar a reprodução das células e minimizar a formação de etanol. Neste trabalho, avaliou-se o crescimento de leveduras Saccharomyces cerevisiae em um equipamento dotado de sistema de aeração pelo processo de batelada simples (descontínuo) e pelo processo semicontínuo, utilizando-se um meio complexo ou um meio agroindustrial. O uso do equipamento com aeração permitiu maior conversão de substrato em célula e reduziu o nível de etanol e acidez produzidos. A propagação realizada pelo processo semicontínuo foi mais eficiente do que o de batelada simples. A utilização de um meio agroindustrial suplementado com uma fonte proteica, tal como geralmente é realizado na propagação de leveduras para produção de cachaça de alambique, forneceu maiores aumentos de biomassa e melhores parâmetros de propagação, quando comparado com um meio complexo. Estes resultados contribuirão para o desenvolvimento de um protocolo operacional de propagação de fermento a ser utilizado para produção de cachaça de alambique.

Palavras-chave: Cachaça; Levedura; Aumento de biomassa; Fermentação.

\section{Summary}

Traditionally, the yeast is propagated directly in the fermentation vats in sugarcane spirit factories. However, they have no devices to optimize the propagation, in which the aeration efficiency is a key factor in the prevalence of the respiratory metabolism to maximize yeast reproduction and minimize the formation of ethanol. This study evaluated the growth of the yeast Saccharomyces cerevisiae in equipment with both simple batch and semi-continuous aeration systems using complex or agro industrial media. The use of aerated equipment allowed for greater substrate conversion to cells and reduced the levels of ethanol and acids produced. The propagation carried out by the semi-continuous process was more efficient than that with the simple batch system. The use of an agro industrial medium supplemented with a protein source, as usually done in the propagation of yeast for the production of sugarcane spirit, provided the greatest increases in biomass and the best parameters for propagation as compared to a complex medium. These results will contribute to the development of an operational protocol for propagation of the yeast to be used in the production of sugarcane spirit.

Key words: Cachaça; Yeast; Biomass increase; Fermentation. 
Aumento na produção de biomassa de levedura em propagador aerado por processo descontínuo e semicontínuo para produção de cachaça

MENDES, T. A. O. et al.

\section{Introdução}

Cachaça é a denominação típica e exclusiva da aguardente de cana-de-açúcar produzida no Brasil (BRASIL, 2005). Embora a produção nacional de cachaça seja quase que totalmente consumida no mercado interno, tem-se verificado um crescimento da sua aceitação no mercado internacional, demonstrando um grande potencial para a exportação (ESTANISLAU et al., 2002). Entretanto, sabe-se que o desconhecimento da ciência envolvida na produção desta bebida limita a quantidade e a qualidade do produto disponibilizado por pequenos produtores, sendo este um dos principais entraves para a exportação de grandes quantidades do produto (MIRANDA et al., 2007).

Basicamente, a produção de cachaça consiste em propagar o fermento, extrair o caldo da cana-deaçúcar na operação de moagem, convertê-lo em vinho pelo processo de fermentação e transformar o vinho em cachaça por meio da destilação (MAIA, 2002). Nos últimos anos, muitos conhecimentos foram adquiridos quanto aos aspectos de extração do caldo, purificação, fermentação, desinfecção e técnicas de destilação (OLIVEIRA et al., 2004, 2005; SILVA et al., 2006; ROSA et al., 2009; LIMA, 2001). Porém, poucos avanços foram obtidos na etapa de propagação das leveduras ou preparo do inóculo.

Durante a multiplicação do fermento natural e no decorrer da fermentação para produção de cachaça de alambique, há uma sucessão de espécies de leveduras, sendo a predominante a Saccharomyces cerevisiae (NOVA et al., 2009; RODRÍGUEZ et al., 2011). Esta espécie é descrita como resistente a altas concentrações de etanol, elevadas temperaturas e baixos valores de $\mathrm{pH}$, características importantes durante o processo de produção da cachaça (CAMPOS et al., 2010). Tradicionalmente, a propagação do fermento é feita diretamente dentro das dornas de fermentação nas fábricas de cachaça de alambique. Estas dornas são apropriadas para a fase anaeróbia do metabolismo das leveduras, quando ocorre predominantemente a fermentação do açúcar em etanol e gás carbônico (MAIA, 2002). Contudo, as dornas não dispõem de quaisquer dispositivos que permitam otimizar a propagação das leveduras, na qual a eficiência da aeração é fator primordial para a predominância do metabolismo respiratório, que permite maximizar a reprodução das células e minimizar a formação de etanol (MAIA, 2002; PATARO et al., 2002). É sabido que o etanol, além de ser inibidor da propagação das leveduras, é o substrato ideal para as bactérias acéticas, que contribuem para diminuir a qualidade do produto (ALVES, 1994; PATARO et al., 2002).

Os processos tradicionais de propagação de leveduras requerem entre 8 e 15 dias, chegando a 30 dias em alguns casos. A principal metodologia utilizada é a de batelada simples, na qual o fermento é deixado em contato com o meio de cultura até obtenção de massa suficiente para realizar a etapa de fermentação (MAIA, 2002). Dispondo de um propagador adequado, o produtor artesanal pode obter fermento suficiente para uma dorna em aproximadamente 24 horas, partindo de $500 \mathrm{~g}$ ou menos do fermento original. Este equipamento permite manter um controle mais eficiente da propagação, substituindo-se as células de uma dorna a intervalos programados ou sempre que houver indícios de contaminação (MAIA, 2002).

A introdução de um equipamento específico para maximizar a etapa de propagação do fermento também abre caminho para a utilização de linhagens selecionadas, o que pode representar um salto de qualidade para a cachaça de alambique. Os trabalhos de isolamento de linhagens apontam excelentes perspectivas para se implementar a qualidade sensorial do destilado (GUERRA et al., 2001; GOMES et al., 2007). No entanto, isso só será viável para os produtores na medida em que disponham de um equipamento adequado para propagação dessas linhagens. Neste trabalho, avaliou-se a propagação de leveduras Saccharomyces cerevisiae em um equipamento para propagação de leveduras, projetado pelo grupo deste trabalho, por processos de batelada simples (descontínuo) e semicontínuo, sob aeração controlada, utilizando meio complexo e meio agroindustrial.

\section{Material e métodos}

\subsection{Propagador}

O propagador consistiu em um cilindro vertical de vidro borossilicato com base em aço inox com $32 \mathrm{~cm}$ de altura e $16 \mathrm{~cm}$ de diâmetro, e uma capacidade de 5 litros (Figura 1). Este equipamento é dotado de um sistema de aeração por meio de um difusor de ar metálico localizado na base, com 100 mm de diâmetro, com orifícios de $1 \mathrm{~mm}$ na parte superior e conectado a um rotâmetro (Figura 1a, b). O equipamento também possui entrada para alimentação de mosto e um sistema para coleta de amostras e retirada do meio de cultivo (Figura 1c). Todos os experimentos foram realizados utilizando-se $80 \%$ da capacidade do propagador (4 litros).

\subsection{Leveduras e meios de cultura}

Fermento fresco prensado (Fleischmann) constituído de células de levedura S. cerevisiae, contendo 30-32 \% de massa seca e viabilidade celular acima de $95 \%$, foi utilizado em todos os experimentos. As propagações foram realizadas em dois meios de cultura diferentes (PELCZAR et al., 1996). O meio complexo foi composto por extrato de levedura $9 \mathrm{~g} . \mathrm{L}^{-1}$, glicose $30 \mathrm{~g} . \mathrm{L}^{-1}$, 
Aumento na produção de biomassa de levedura em propagador aerado por processo descontínuo e semicontínuo para produção de cachaça

MENDES, T. A. O. et al.

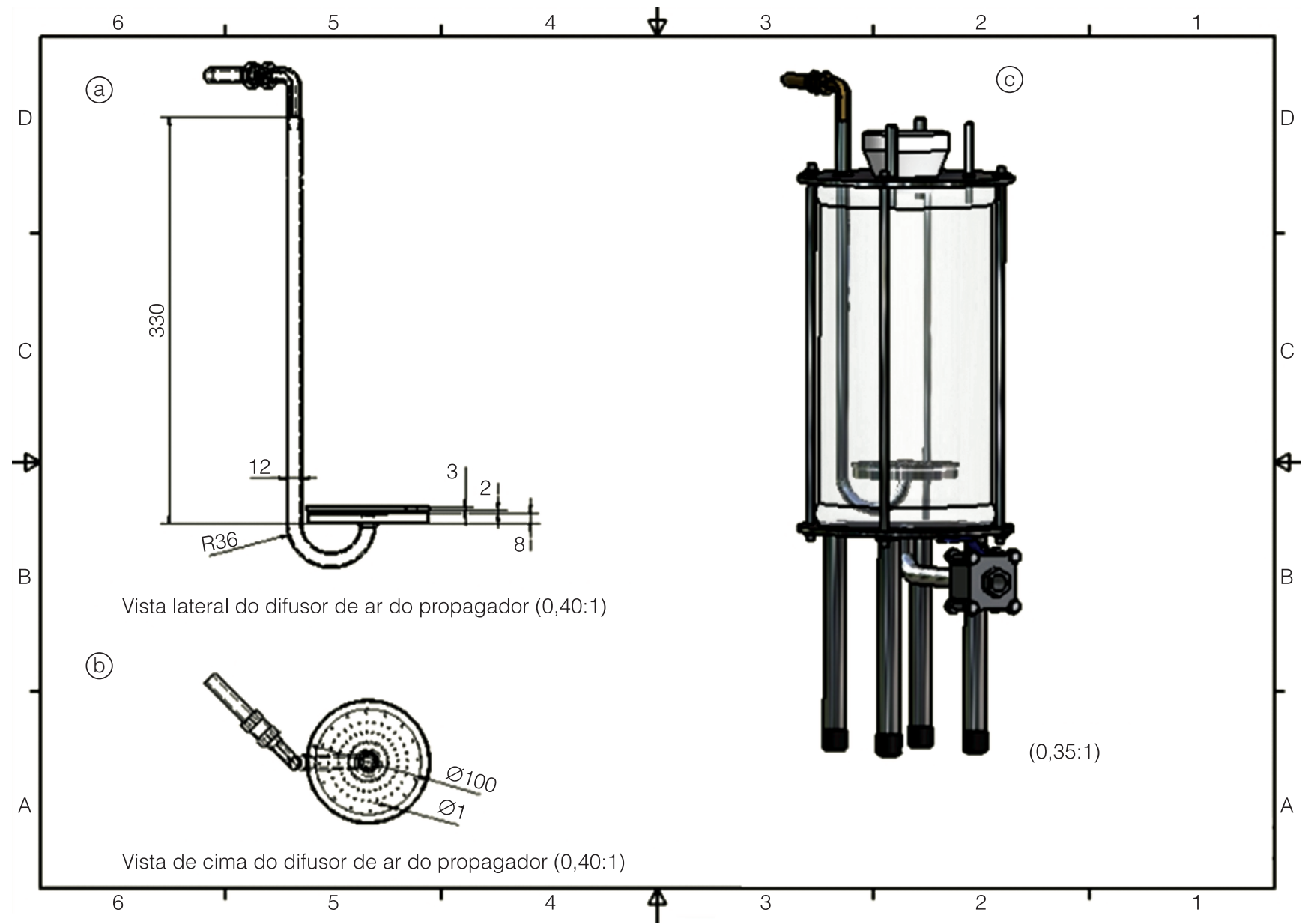

Figura 1. Esquema do equipamento com sistema de aeração para propagação de leveduras S. cerevisiae. a) Vista lateral do difusor de ar. b) Vista de cima do difusor de ar. c) Esquema geral do propagador. 1, local de conexão ao rotâmetro; 2, entrada para alimentação de mosto; 3 , sistema para coleta de amostras e retirada do meio de cultivo.

$\left(\mathrm{NH}_{4}\right)_{2} \mathrm{SO}_{4} 2 \mathrm{~g} \cdot \mathrm{L}^{-1}, \mathrm{NH}_{4} \mathrm{Cl}_{2} \mathrm{~g} \cdot \mathrm{L}^{-1}$ e $\mathrm{MgSO}_{4} \cdot 7 \mathrm{H}_{2} \mathrm{O} 0,5 \mathrm{~g} \cdot \mathrm{L}^{-1}$ (OLIVEIRA et al., 2004). O meio agroindustrial utilizado foi composto de caldo de cana-de-açúcar diluído a uma concentração de 30 g. $L^{-1}$ de açúcares redutores totais (ART) e suplementando com extrato de levedura $9 \mathrm{~g} . \mathrm{L}^{-1}$ como fonte de nitrogênio proteico (PULZATTO, 2000). Ambos os meios foram esterilizados em autoclave a $120{ }^{\circ} \mathrm{C}$ por 30 minutos. Em todos os experimentos, foi utilizado um inóculo de 0,12 g em massa seca do fermento por litro de meio de cultura (MALTA, 2006).

\subsection{Testes de propagação}

A propagação da levedura Saccharomyces cerevisiae foi testada sob três diferentes condições, em um propagador com sistemas de aeração conforme resumidos na Tabela 1, quais sejam: i) No primeiro experimento, foi realizada a propagação da levedura por 24 horas pelo processo de batelada simples em meio complexo, com aeração controlada de $10 \mathrm{~nL} \cdot \mathrm{min}^{-1}$ e sem aeração; ii) $\mathrm{O}$ segundo experimento foi realizado por 48 horas, utilizando-se meio complexo com aeração controlada de $10 \mathrm{~nL} \cdot \mathrm{min}^{-1}$ pelos processos de batelada simples e semicontínuo. No processo semicontínuo, após 24 horas de propagação, três quartos do volume do meio de cultura (3 litros) foram retirados do propagador, seguido pela adição da mesma quantidade do meio estéril; iii) O terceiro experimento foi realizado pelo processo semicontínuo com aeração controlada de 10 nL. min $^{-1}$ por 96 horas, utilizando-se meio complexo e meio agroindustrial.

A temperatura, o pH e a quantidade de oxigênio dissolvido foram monitorados durante todo o período das diferentes propagações por termômetro de mercúrio, pHmetro (QUIMIS, modelo Q400A) e oxímetro (INSTRUTHERM, modelo MO-880), respectivamente. Em todos os experimentos, foram calculados os seguintes parâmetros da fermentação: viabilidade celular; fator de conversão de substrato em célula $\left(Y_{\mathbf{x} / \mathbf{s}}\right)$; fator de conversão de substrato em etanol $\left(Y_{\mathrm{p} / \mathrm{s}}\right)$; fator de conversão de substrato em acidez $\left(Y_{\text {ac/s }}\right)$, e aumento de biomassa. 
Aumento na produção de biomassa de levedura em propagador aerado por processo descontínuo e semicontínuo para produção de cachaça

MENDES, T. A. O. et al.

Tabela 1. Condições experimentais de propagação de S. cerevisiae.

\begin{tabular}{cccccc} 
Experimentos & $\begin{array}{c}\text { Grupos } \\
\text { experimentais }\end{array}$ & $\begin{array}{c}\text { Tempo de } \\
\text { propagação }(\mathbf{h})\end{array}$ & Processo & $\begin{array}{c}\text { Aeração } \\
\left(\mathbf{n L} \mathbf{m i n}^{-1}\right)\end{array}$ & Meio de cultura \\
\hline 1 & A & 24 & Batelada simples & Sem aeração & Complexo \\
2 & B & 24 & Batelada simples & 10 & Complexo \\
& A & 48 & Batelada simples & 10 & Complexo \\
3 & B & 48 & Semicontínuo & 10 & Complexo \\
& A & 96 & Semicontínuo & 10 & Complexo \\
& B & 96 & Semicontínuo & 10 & Agroindustrial \\
\hline
\end{tabular}

\subsection{Viabilidade celular}

A viabilidade celular foi determinada utilizando-se a metodologia descrita por Bonneu et al. (1991), seguida de contagem em câmara de Neubauer em microscópio óptico.

\subsection{Fator de conversão de substrato em célula $\left(\mathrm{Y}_{\mathrm{x} / \mathrm{s}}\right)$}

O fator de conversão de substrato em célula $\left(Y_{x / s}\right)$ fornece a quantidade de massa celular produzida por grama de açúcar consumido e é calculado pela seguinte fórmula (MAIA, 2002):

$Y_{x / s} \frac{X_{F}-X_{O}}{S_{F}-S_{O}}$

em que: $S_{O}$ e $S_{F}$ representam a massa de ART $(g) ; X_{0} e$ $X_{F}$ representam a massa seca do fermento (g) no início e no final do processo, respectivamente.

A massa seca do fermento foi determinada por secagem em estufa a $105{ }^{\circ} \mathrm{C}$ até peso constante (TIBAYRENC et al., 2011). A determinação de ART foi realizada pela metodologia do ácido 3,5 dinitrosalicílico (DNS) proposta por Miller (1959).

\subsection{Fator de conversão de substrato em etanol $\left(\mathrm{Y}_{\mathrm{p} / \mathrm{s}}\right)$}

$\mathrm{O}$ fator de conversão de substrato em etanol $\left(\mathrm{Y}_{\mathrm{p} / \mathrm{s}}\right)$ expressa a quantidade de etanol formada por unidade de açúcar consumido e calculado pela seguinte expressão (MAIA, 2002):

$Y_{p / s}=\frac{P_{F}-P_{O}}{S_{F}-S_{O}}$

em que: $P_{0}$ e $P_{F}$ representam a massa etanol $(\mathrm{g}) ; S_{0}$ e $S_{F}$ representam a massa de ART (g) no início e no final da propagação, respectivamente. Inicialmente, o etanol foi separado do meio por destilação por arraste de vapor em microdestilador de álcool (Tecnal, modelo TE-012). Em seguida, a concentração de etanol foi determinada pelo método descrito na ABNT, 1997b.

\subsection{Fator de conversão de substrato em acidez $\left(\mathrm{Y}_{\text {ac/s }}\right)$}

O fator de conversão de substrato em acidez $\left(\mathrm{Y}_{\mathrm{ac} / \mathrm{s}}\right)$ expressa a quantidade de ácido formada por unidade de açúcar consumido e foi calculado pela seguinte expressão (MAIA, 2002):

$$
Y_{p / s}=\frac{A c_{F}-A c_{O}}{S_{F}-S_{O}}
$$

em que: $A c_{o}$ e $A c_{F}$ representam a massa de acidez total expressa em acético $(\mathrm{g})$; $\mathrm{S}_{\mathbf{O}}$ e $\mathrm{S}_{\mathbf{F}}$ representam a massa de ART (g) no início e no final da propagação, respectivamente.

A acidez total foi determinada conforme ABNT, 1997a. O aumento de biomassa foi calculado pela razão entre o valor de massa seca celular determinado no tempo inicial e no tempo final de cada experimento, e este aumento foi expresso em número de vezes.

\subsection{Análise estatística}

Cada experimento foi realizado seis vezes e a média e o desvio padrão de cada grupo experimental foram calculados. A análise estatística foi realizada utilizando-se o software GraphPad Prism 5.0 $0^{\circledR}$. Inicialmente, a distribuição gaussiana dos dados foi confirmada pelo teste de Kolmogorov-Smirnov. Os resultados foram então submetidos ao Teste t, considerando um valor-p significativo menor que 0,05 .

\section{Resultados e discussão}

Uma vez que as dornas utilizadas para propagação em alambiques não possuem sistemas de aeração (MAIA, 2002; PATARO et al., 2002), testou-se o efeito da aeração controlada sobre a propagação em batelada simples de leveduras Saccharomyces cerevisiae. A temperatura foi de aproximadamente $24 \pm 2{ }^{\circ} \mathrm{C}$ durante todo o processo, o pH inicial de $5,9 \pm 0,9$ e o oxigênio dissolvido, 3,6 $\pm 0,2 \mathrm{mg} \cdot \mathrm{L}^{-1}$. Os resultados desta propagação se encontram na Tabela 2 e na Figura 2. 0 aumento de biomassa foi significativamente maior quando 
Aumento na produção de biomassa de levedura em propagador aerado por processo descontínuo e semicontínuo para produção de cachaça

MENDES, T. A. O. et al.

Tabela 2. Parâmetros de propagação em batelada simples da levedura Saccharomyces cerevisiae por 24 horas, em meio complexo aerado e não aerado.

\begin{tabular}{lccccc} 
& Viabilidade (\%) & Oxigênio dissolvido (mg/L) & $\mathbf{Y}_{\mathbf{x / s}} \mathbf{b}^{* *}$ & $\mathbf{Y}_{\mathrm{p} / \mathbf{s}}{ }^{* * *}$ & $\mathbf{Y}_{\mathrm{ac/s}}{ }^{* * *}$ \\
Meio aerado & $96 \pm 8$ & $10,1 \pm 0,9^{(\mathrm{a})}$ & $0,41 \pm 0,02^{(\mathrm{a})}$ & $0,03 \pm 0,02^{(\mathrm{b})}$ & $0,006 \pm 0,001^{(\mathrm{b})}$ \\
Meio não aerado & $98 \pm 6$ & $1,2 \pm 0,6^{(\mathrm{b})}$ & $0,12 \pm 0,07^{(\mathrm{b})}$ & $0,09 \pm 0,02^{(\mathrm{a})}$ & $0,05 \pm 0,02^{(\mathrm{a})}$ \\
\hline
\end{tabular}

Letras distintas na mesma coluna indicam que os valores diferem entre si a ${ }^{\star} p<0,05,{ }^{* *} p<0,01 e^{* \star *} p<0,001$.

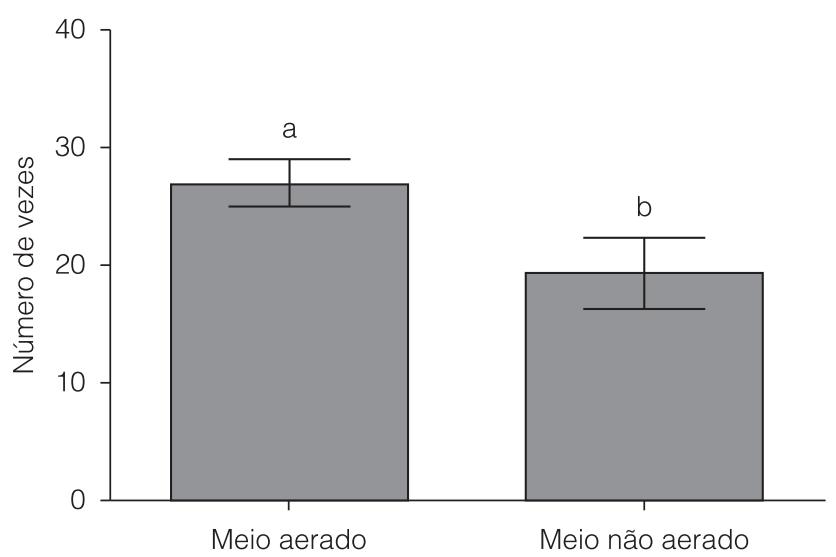

Figura 2. Aumento de biomassa da levedura Saccharomyces cerevisiae após 24 horas de propagação em meio complexo com aeração controlada de $10 \mathrm{~nL} \cdot \mathrm{min}^{-1}$ ou não aerado. Letras distintas indicam que os valores diferem entre si a $p<0,05$.

a propagação foi mantida com aeração de $10 \mathrm{~nL} \cdot \mathrm{min}^{-1}$ (Figura 2). Com a aeração, houve direcionamento do metabolismo energético para a respiração celular, com maior produção de ATP e, consequentemente, maior quantidade de energia disponível para multiplicação celular e aumento de biomassa (FERNDAHL et al., 2010). Na propagação sem aeração, houve redução significativa do oxigênio dissolvido, o que resultou no aumento da atividade fermentativa das leveduras (MAIA, 2002), observado pelo aumento no fator de conversão de substrato em etanol $\left(Y_{p / s}\right)$, conforme observado na Tabela 2. A fermentação produz menor quantidade de energia, contribuindo para a redução da taxa de multiplicação celular (MAIA, 2002; PATARO et al., 2002). Também houve um aumento de 8,3 vezes no fator de conversão de substrato em acidez $\left(Y_{\text {ac/s }}\right)$. O ácido acético é principalmente formado na via fermentativa pela oxidação do acetaldeído proveniente da oxidação do etanol (SAINT-PRIX et al., 2004). Com o aumento da aeração nas etapas iniciais de propagação, o metabolismo energético é direcionado para o processo de respiração celular (FERNDAHL et al., 2010), o que resulta em menor formação de etanol. Com a redução do substrato, há consequentemente redução da formação dos produtos acetaldeído e ácido acético (SAINT-PRIX et al., 2004). Assim, a elevação na quantidade de etanol produzida na propagação não aerada pode ter favorecido o crescimento de bactérias que metabolizaram o etanol a ácidos orgânicos, contribuindo para o aumento do valor de $Y_{\text {ac/s }}$. Com 24 horas de propagação utilizadas, não houve diferença significativa quanto à viabilidade celular. Porém, como a produção de etanol foi significativamente maior na propagação não aerada, é provável que a concentração inibitória seja alcançada mais rapidamente e reduza ainda mais o valor de aumento de biomassa produzido ao longo do tempo.

Com base nos resultados de incremento da biomassa no meio aerado no ensaio experimental seguinte, comparou-se o processo descontínuo de propagação com o semicontínuo. Os resultados se encontram na Tabela 3 e na Figura 3. A propagação por processo descontínuo resultou em menor aumento de biomassa, após 48 horas (Figura 3). Neste método de propagação, ao longo do tempo, houve consumo do substrato e da concentração dos metabólitos inibidores do processo de multiplicação de leveduras, como o etanol e os ácidos orgânicos, resultando na diminuição de produção de biomassa. O acúmulo destes metabólicos também pode ter contribuído para a diminuição da viabilidade celular obtida em 48 horas de propagação por batelada simples. Por outro lado, a utilização do processo de propagação semicontínuo resultou em um maior aumento de biomassa (Figura 3), aumento da viabilidade, aumento da produção de célula representado pelo parâmetro $Y_{x / s}$ e diminuição da conversão de açúcares em etanol $\left(Y_{p / s}\right)$, provavelmente resultante da renovação dos substratos e do controle do número de células de levedura no meio.

A utilização de um meio complexo definido para a etapa de propagação de fermento é inviável e pouco rotineiro em fábricas de cachaça. Geralmente, são utilizados meios agroindustriais, como caldo de canade-açúcar suplementado com uma fonte proteica. Tal suplementação é realizada porque o nitrogênio proteico presente no caldo é insuficiente para suprir a nutrição da levedura (JERONIMO et al., 2008). A fonte proteica mais utilizada por pequenos produtores é o fubá, que oferece alguns benefícios, como a adsorção pelo amido de metabólitos secundários da própria fermentação alcoólica, resultando em aguardente com menor acidez total, considerada de melhor qualidade (MAIA, 2002; JERONIMO et al., 2008; JOHANSSON et al., 2011). 
Aumento na produção de biomassa de levedura em propagador aerado por processo descontínuo e semicontínuo para produção de cachaça

MENDES, T. A. O. et al.

Tabela 3. Parâmetros de propagação em batelada simples ou processo semicontínuo da levedura Saccharomyces cerevisiae por 24 e 48 horas, em meio complexo aerado.

\begin{tabular}{|c|c|c|c|c|c|}
\hline & \multicolumn{5}{|c|}{24 horas } \\
\hline & Viabilidade (\%) & Oxigênio dissolvido (mg/L) & $\mathbf{Y}_{\mathrm{x} / \mathrm{s}}$ & $Y_{p / s}$ & $\mathbf{Y}_{\mathrm{ac} / \mathrm{s}}$ \\
\hline Descontínuo & $96 \pm 9$ & $8,2 \pm 0,6$ & $0,43 \pm 0,03$ & $0,09 \pm 0,05$ & $0,002 \pm 0,001$ \\
\hline \multirow[t]{3}{*}{ Semicontínuo } & $95 \pm 4$ & $7,8 \pm 0,4$ & $0,38 \pm 0,04$ & $0,08 \pm 0,03$ & $0,005 \pm 0,003$ \\
\hline & \multicolumn{5}{|c|}{48 horas } \\
\hline & Viabilidade $(\%)^{*}$ & Oxigênio dissolvido (mg/L) & $Y_{x / s} b^{*}$ & $Y_{p / s}^{*}$ & $Y_{\mathrm{ac} / \mathrm{s}}{ }^{\star \star}$ \\
\hline Descontínuo & $73 \pm 3$ & $8,1 \pm 0,7$ & $0,21 \pm 0,02^{(\mathrm{b})}$ & $0,17 \pm 0,04^{(a)}$ & $0,03 \pm 0,01^{(a)}$ \\
\hline Semicontínuo & $98 \pm 7$ & $9,2 \pm 0,6$ & $0,39 \pm 0,06^{(a)}$ & $0,01 \pm 0,02^{(b)}$ & $0,012 \pm 0,002^{(b)}$ \\
\hline
\end{tabular}

Letras distintas na mesma coluna indicam que os valores diferem entre si $a^{*} p<0,01 e^{* *} p<0,05$.
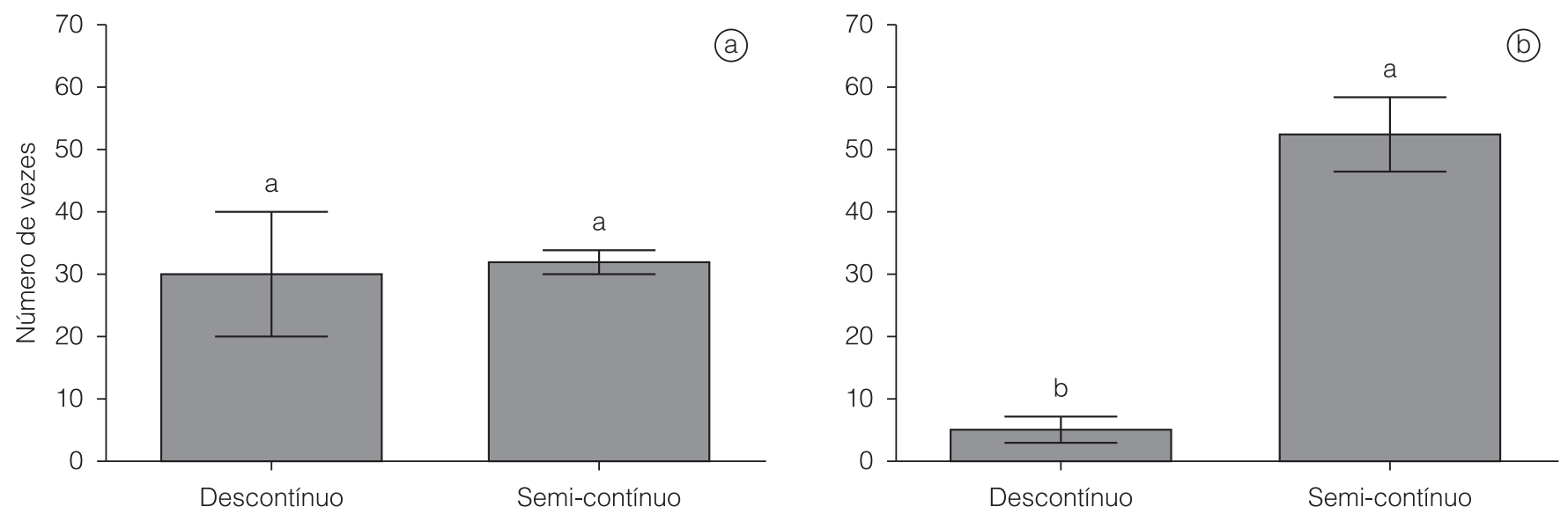

Figura 3. Aumento de biomassa da levedura Saccharomyces cerevisiae por propagação em meio complexo com aeração controlada de $10 \mathrm{~nL}$. $\mathrm{min}^{-1}$ utilizando processos descontínuo e semicontínuo. a) Após 24 horas; b) Após 48 horas. Letras distintas indicam que os valores diferem entre si a $\mathrm{p}<0,001$.

No entanto, Pulzatto (2000) e Jeronimo et al. (2008) verificaram que a suplementação do caldo de cana com extrato de levedura influenciou positivamente o rendimento em massa celular e a manutenção da viabilidade celular durante a fermentação alcoólica. Por este motivo, no último experimento, comparou-se o efeito de um meio agroindustrial suplementado com extrato de levedura com um meio complexo sobre os parâmetros da propagação da levedura $S$. cerevisiae por processo semicontínuo, durante 96 horas. O meio agroindustrial era composto de caldo de cana-de-açúcar diluído a uma concentração de $30 \mathrm{~g} \cdot \mathrm{L}^{-1}$ de açúcares redutores totais e acrescentado de extrato de levedura $9 \mathrm{~g} . \mathrm{L}^{-1}$ como fonte de proteína. Não houve diferença significativa entre a maioria dos parâmetros de propagação analisados (Figura 4a-e). Entretanto, foi observado um aumento significativo na quantidade de biomassa obtida utilizando-se o meio agroindustrial suplementado a partir de 48 horas de propagação (Figura 4f). O meio agroindustrial é mais complexo, possuindo alguns microelementos não presentes no meio complexo, como íons inorgânicos (MAIA, 2002). As leveduras exigem estes íns em concentrações tanto $\mu \mathrm{M}$ como mM para alcançar maiores aumento de biomassa e rendimento fermentativo. Microelementos têm uma função importante no metabolismo celular, principalmente em função dos seus requerimentos como cofatores para várias enzimas (STEHLIK-TOMAS et al., 2004). Deficiências ou concentrações elevadas de tais minerais provocam alterações metabólicas significativas (SCHMIDT et al., 2011). Assim, o meio contendo caldo de cana-de-açúcar suplementado pode ter fornecido elementos importantes para multiplicação de leveduras, não presentes no meio complexo, resultando em um aumento na produção de biomassa. Sob condições estritamente aeróbias, Reed e Nagodawithana (1991) obtiveram um $Y_{x / s}$ de 0,54 utilizando equipamentos com controles de temperatura, aeração e agitação para propagação; diversamente, neste trabalho, os valores obtidos de $Y_{x / s}$ foram similares utilizando-se um equipamento mais simples, somente com aeração controlada e um meio agroindustrial suplementado, o que reduz o custo da produção de cachaça. 
Aumento na produção de biomassa de levedura em propagador aerado por processo descontínuo e semicontínuo para produção de cachaça

MENDES, T. A. O. et al.
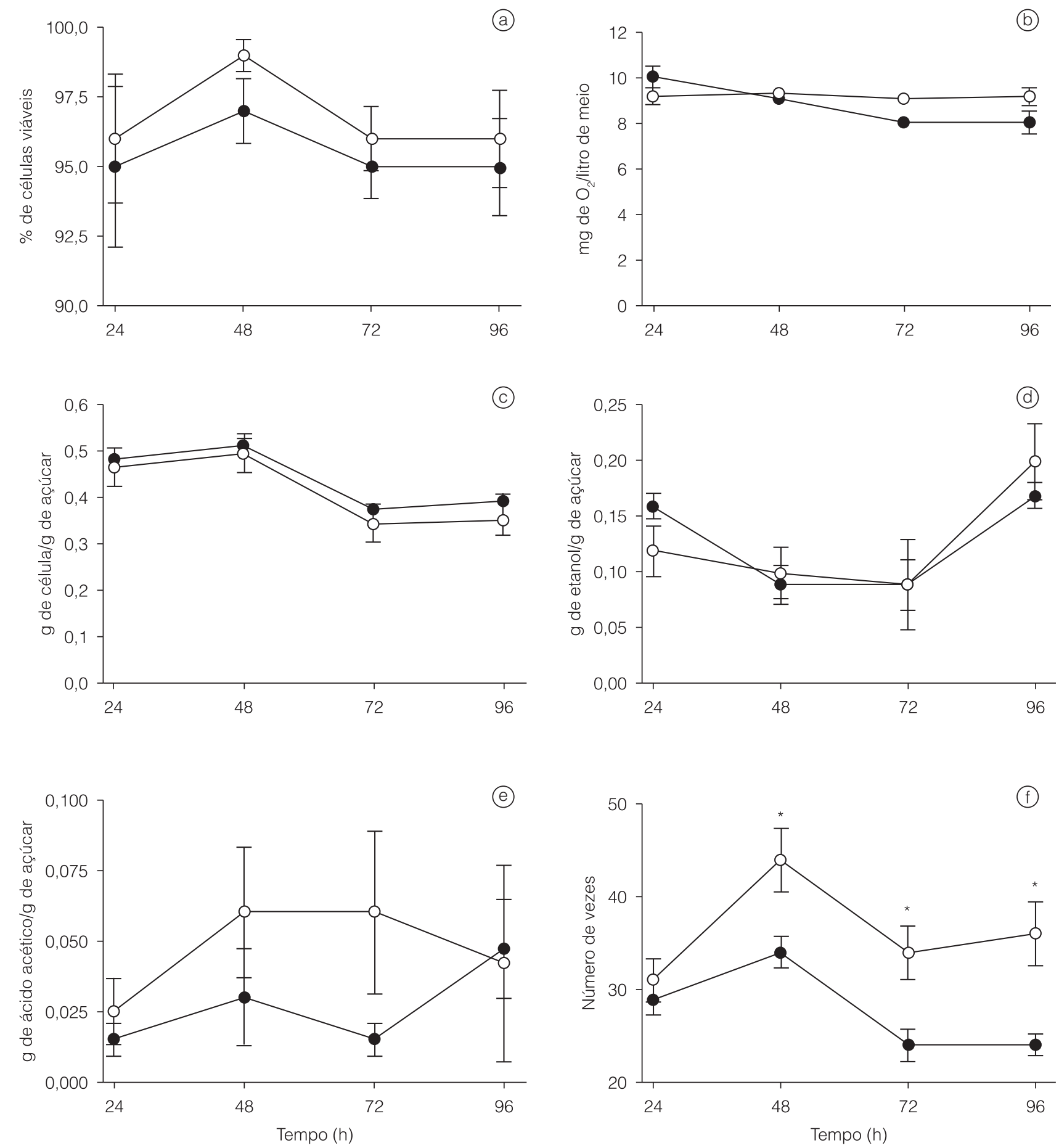

$\rightarrow$ Meio complexo -o- Meio agroindustrial suplementado

Figura 4. Parâmetros de propagação da levedura Saccharomyces cerevisiae por processo semicontínuo em meio complexo ou agroindustrial suplementado, com aeração controlada de $10 \mathrm{~nL} \cdot \mathrm{min}^{-1}$ ao longo de 96 horas. a) Viabilidade celular. b) Oxigênio dissolvido. c) $Y_{x / s^{*}}$ d) $Y_{p / s}$. e) $Y_{a c / s}$. f) Aumento de biomassa. ${ }^{*} p<0,05$.

\section{Conclusão}

Os resultados demonstraram que o uso de um equipamento com aeração incrementou o aumento de biomassa, bem como reduziu o nível de etanol e a acidez produzidos na etapa de propagação do fermento. Na medida em que elevada acidez volátil é um problema recorrente nas cachaças de alambique, o uso de aeração nesta etapa pode não só acelerar a obtenção de células de levedura para a etapa de fermentação como também contribuir para a redução da acidez no produto final, melhorando a sua qualidade. O processo semicontínuo 
Aumento na produção de biomassa de levedura em propagador aerado por processo descontínuo e semicontínuo para produção de cachaça

MENDES, T. A. O. et al.

de propagação foi mais eficiente no aumento de biomassa e na manutenção da viabilidade celular de levedura do que o processo descontínuo. A utilização de um meio agroindustrial suplementado, tal como realizado em alambiques, também forneceu vantagens na obtenção de biomassa, quando comparado com um meio complexo quimicamente definido. Todos os resultados irão contribuir para o desenvolvimento de um protocolo operacional de propagação de fermento que possa ser utilizado para produção de cachaça de alambique.

\section{Agradecimentos}

Os autores agradecem ao CNPq e à FAPEMIG, pelo apoio financeiro na realização deste estudo.

\section{Referências}

ASSOCIAÇÃO BRASILEIRA DE NORMAS TÉCNICAS - ABNT. NBR 13856: Acidez Titulável Total, Volátil Total e Fixa. São Paulo: ABNT, 1997a. 4 p.

ASSOCIAÇÃO BRASILEIRA DE NORMAS TÉCNICAS - ABNT. NBR 13920: Determinação do Teor Alcoólico. São Paulo: ABNT, 1997b. 4 p.

ALVES, D. M. G. Fatores que Afetam a Produção de Ácidos Orgânicos bem Como Outros Parâmetros da Fermentação Alcoólica. 1994. 251 f. Dissertação (Mestrado em Fisiologia e Bioquímica de Plantas)-Escola Superior de Agricultura "Luiz de Queiroz", Universidade de São Paulo, Piracicaba, 1994.

BONNEU, M.; CROUZET, M.; URDACI, M.; AIGLE, M. Direct selection of yeast mutants with reduced viability on plates by eritrosine B. staining. Analytical Biochemistry, Maryland Heights, v. 193, n. 2, p. 225-230, 1991.

BRASIL. Ministério da Agricultura, Pecuária e Abastecimento. Instrução Normativa $n^{\circ} 13$, de 29 de junho de 2005. Aprova o Regulamento Técnico para a fabricação de bebidas e vinagres, inclusive vinhos e derivados da uva e do vinho, dirigido a estabelecimentos elaboradores e ou industrializadores. Diário Oficial da República Federativa do Brasil, Brasília, DF, 30 jun 2005. Seção 1, p. 3.

CAMPOS, C. R.; SILVA, C. F.; DIAS, D. R.; BASSO, L. C.; AMORIM, H. V.; SCHWAN, R. F. Features of Saccharomyces cerevisiae as a culture starter for the production of the distilled sugar cane beverage, cachaça in Brazil. Journal of Applied Microbiology, Malden, v. 108, n. 6, p. 1871-1879, 2010.

ESTANISLAU, M. L. L.; CANÇADO-JUNIOR, F. L.; PAIVA, B. M. Mercado atual e potencial da cachaça. Informe Agropecuário, Belo Horizonte, v. 23, n. 217, p. 19-24, 2002

FERNDAHL, C.; BONANDER, N.; LOGEZ, C.; WAGNER, R.; GUSTAFSSON, L.; LARSSON, C.; HEDFALK, K.; DARBY, R. A.; BILL, R. M. Increasing cell biomass in Saccharomyces cerevisiae increases recombinant protein yield: the use of a respiratory strain as a microbial cell factory. Microbial Cell Factories, London, v. 9, n. 47, p. 11, 2010. (on line)

GOMES, F. C.; SILVA, C. L.; MARINI, M. M.; OLIVEIRA, E. S.; ROSA, C. A. Use of selected indigenous Saccharomyces cerevisiae strains for the production of the traditional cachaça in Brazil. Journal of Applied Microbiology, Malden, v. 103, n. 6, p. 2438-2447, 2007. http://dx.doi.org/10.1111/j.13652672.2007.03486.x

GuERRA, J. B.; ARAÚJO, R. A. C.; PATARO, C.; FRANCO, G. R.; MOREIRA, E. S. A.; MENDONÇA-HAGLER, L. C.; ROSA, C. A. Genetic diversity of Saccharomyces cerevisiae strains during the $24 \mathrm{~h}$ fermentative cycle for the production of the arthisanal Brasilian cachaça. Letters in Applied Microbiology, Malden, v. 33, n. 2, p. 106-111, 2001. http://dx.doi.org/10.1046/j.1472765x.2001.00959.x

JERONIMO, E. M.; OLIVEIRA, E. S.; SOUZA, E. L. R.; SILVA, M. A.; SERRA, G. E. Addition of Proteic Nitrogen during Alcoholic Fermentation for the Production of Cachaça. Scientia Agrícola, Piracicaba, v. 65, n. 2, p. 161-168, 2008.

JOHANSSON, E.; BRANDBERG, T.; LARSSON, C. Influence of cultivation procedure for Saccharomyces cerevisiae used as pitching agent in industrial spent sulphite liquor fermentations. Journal of Industrial Microbiology and Biotechnology, Heidelberg, v. 38, n. 11, p. 565-571, 2011.

LIMA, U. A. Aguardentes. In: AQUARONE, E.; LIMA, U. A.; BORZANI, W. (Eds.). Biotecnologia Industrial. 2. ed. São Paulo: Edgard Blücher, 2001. v. 4, cap. 5, p. 145-182.

MAIA, A. B. R. A. Equipamentos para a produção de cachaça. Informe Agropecuário, Belo Horizonte, v. 23, n. 217 , p. 63-66, 2002.

MALTA, H. L. Estudos de Parâmetros de Propagação de Fermento (Saccharomyces Cerevisiae) para Produção de Cachaça de Alambique. 2006. 70 f. Dissertação (Mestrado em Ciência de Alimentos)-Faculdade de Farmácia, Universidade Federal de Minas Gerais, Belo Horizonte, 2006.

MILLER, G. L. Use of dinitrosalicylic acid reagent for determination or reducing sugar. Analytical Chemistry, Urbana, v. 31, n. 3, p. 426-428, 1959. http://dx.doi.org/10.1021/ ac60147a030

MIRANDA, M. B.; MARTINS, N. G. S.; BELLUCO, A. E. S.; HORII, J.; ALCARDE A. R. Qualidade química de cachaças e aguardentes brasileiras. Ciência e Tecnologia de Alimentos, Campinas, v. 27, n. 4, p. 897-901, 2007. http://dx.doi. org/10.1590/S0101-20612007000400034

NOVA, M. X. V.; SCHULER, A. R. P.; BRASILEIRO B. T. R. V.; MORAIS-JUNIOR, M. A. M. Yeast species involved in artisanal cachaça fermentation in three stills with different technological levels in Pernambuco, Brazil. Food Microbiology, Summit-Argo, v. 26, n. 5, p. 460-466, 2009. 
Aumento na produção de biomassa de levedura em propagador aerado por processo descontínuo e semicontínuo para produção de cachaça

MENDES, T. A. O. et al.

OLIVEIRA, E. S.; ROSA, C. A.; MORGANO, M. A.; SERRA, G. E. Fermentation characteristics as criteria for selection of cachaça yeast. World Journal of Microbiology and Biotechnology, Dordrecht, v. 20, n. 1, p. 19-24, 2004. http://dx.doi.org/10.1023/ B:WIBI.0000013286.30695.4e

OLIVEIRA, E. S.; CARDELLO, H. N. A. B.; JERÔNIMO, E. M.; SOUZA, E. L. R.; SERRA, G. E. The influence of different yeast fermentation, composition and sensory quality of cachaça. World Journal of Microbiology and Biotechnology, Dordrecht, v. 21, n. 5, p. 707-715, 2005. http://dx.doi.org/10.1007/s11274004-4490-4

PATARO, C.; GOMES, F. C .O.; ARAÚJO, R. A. C.; ROSA, C. A.; SCHWAN, R. F.; CAMPOS, C. R.; CLARET, A. S.; CASTRO, H. A. Utilização de leveduras selecionadas na fabricação da cachaça de alambique. Informe Agropecuário, Belo Horizonte, v. 23, n. 217, p. 37-43, 2002.

PELCZAR, M. J.; CHAN, E. C. S.; KRIEG, N. R. Microbiologia: Conceitos e Aplicações. 2. ed. São Paulo: Makron Books Editora, 1996. 556 p.

PULZATTO, M. E. Fatores que Influem na Obtenção de Biomassa de Levedura Seca (Saccharomyces Cerevisiae) da Fermentação Alcoólica. 2000. 112 f. Tese (Doutorado em Tecnologia de Alimentos)-Faculdade de Engenharia de Alimentos, Universidade Estadual de Campinas, Campinas, 2000.

REED, G.; NAGODAWITHANA, T. W. Yeast Technology. 2nd ed. New York: Van Nostrand Reinhold, 1991. 454 p.

RODRÍGUEZ, M. E.; INFANTE, J. J.; MOLINA, M.; REBORDINOS, L.; CANTORAL, J. M. Using RFLP-mtDNA for the rapid monitoring of the dominant inoculated yeast strain in industrial wine fermentations. International Journal of Food Microbiology, Torino, v. 145, n. 1, p. 331-335, 2011. http://dx.doi.org/10.1016/j. ijfoodmicro.2010.11.035
ROSA, C. A.; SOARES, A. M.; FARIA, J. B. Cachaça production. In: INGLEDEW, W. M. (Ed.). The Alcohol Textbook. 5th ed. Nottingham: Nottingham University Press, 2009. cap. 42, p. 484-497.

SAINT-PRIX, F.; BÖNQUIST, L.; DEQUIN, S. Functional analysis of the ALD gene family of Saccharomyces cerevisiae during anaerobic growth on glucose: the NADP+-dependent Ald6p and Ald5p isoforms play a major role in acetate formation. Microbiology, Reading, v. 150, n. 7, p. 2209-2220, 2004. http:// dx.doi.org/10.1099/mic.0.26999-0

SCHMIDT, S. A.; DILLON, S.; KOLOUCHOVA, R.; HENSCHKE, P. A.; CHAMBERS, P. J. Impacts of variations in elemental nutrient concentration of Chardonnay musts on Saccharomyces cerevisiae fermentation kinetics and wine composition. Applied Microbiology and Biotechnology, Münster, v. 90, n. 2, p. 679-687, 2011.

SILVA, C. L. C.; ROSA, C. A.; OLIVEIRA, E. S. Studies on the kinetic parameters for alcoholic fermentation by flocculent Saccharomyces cerevisiae strains and nonhydrogen sulphide producing strains. World Journal of Microbiology \& Biotechnology, Dordrecht, v. 22, n. 8, p. 857-863, 2006. http:// dx.doi.org/10.1007/s11274-005-9115-z

STEHLIK-TOMAS, V.; ZETIC, V. G.; STANZER, D.; GRBA, S.; VAHCIC, N. Zn, Cu and Mn Enrichment in S. cerevisiae. Food Technology and Biotechnology, Zagreb, v. 42, n. 2 , p. 115-120, 2004.

TIBAYRENC, P.; GHOMMIDH, C.; PREZIOSI-BELLOY, L. Determination of yeast viability during a stress-model alcoholic fermentation using reagent-free microscopy image analysis. Biotechnology Progress, Malden, v. 27, n. 2, p. 539-46, 2011. http://dx.doi.org/10.1002/btpr.549 